\title{
GENÉTICA TEXTUAL: UM ESTUDO DOS TIPOS E FUNÇÕES DAS RASURAS EM MANUSCRITOS DE ALUNOS RECÉM- ALFABETIZADOS
}

\section{TEXTUAL GENETICS: A STUDY ON TYPES AND FUNCTIONS IN NEWLY LITERACY STUDENTS 'MANUSCRIPTS}

\author{
Dayane Rocha de Oliveira ${ }^{1}$ \\ Universidade Federal de Alagoas (UFAL) \\ Sônia Cristina Simões Felipeto ${ }^{2}$ \\ Universidade Federal de Alagoas (UFAL)
}

\section{RESUMO}

O presente artigo analisa as rasuras que surgem em processos de produção textual realizados em sala de aula dos quais participam duplas que escrevem colaborativamente. Apoiado na Genética textual, através de uma abordagem enunciativa, este estudo elege como categorias de análise os tipos e as funções de rasuras e tem por objetivos: a) a análise e classificação das rasuras em dois processos de criação textual dos quais participam alunas do $2^{\circ}$ ano do ensino básico, de uma escola da cidade de Maceió, AL - Brasil - e alunas do $2^{\circ}$ ano do ensino fundamental de uma escola da cidade de Aveiro - Portugal, todas com 7 anos de idade, cujos dados foram captados através do Sistema Ramos, um dispositivo de captura multimodal em tempo e espaço real da sala de aula; b) em segundo lugar, comparar e discutir as nomenclaturas, os tipos e as funções das rasuras já existentes tendo em vista a variação existente na área; e, c) por fim, verificar quais mais ocorrem, comparando alunos brasileiros com alunos portugueses. Uma vez que o protocolo para a coleta de dados utilizado nos dois países foi o mesmo, importa-nos responder quais funções são mais utilizadas e sobre o que incidem as rasuras nos dois grupos.

PALAVRAS-CHAVE: Genética textual. Funções da rasura. Processo de criação. Tipos de rasura.

\begin{abstract}
This article analyzes the erasures that arise in textual production processes carried out in the classroom, in which pairs collaboratively write. Supported by textual genetics, through an enunciative approach, this study chooses the types and functions of erasures as categories of analysis and aims to: a) analyze and classify erasures in two textual creation processes in which 2nd graders participate. year of basic education, from a school in the city of Maceió, AL - Brazil - and students of the 2nd year of elementary school in a school in the city of Aveiro - Portugal, all aged 7, whose data were captured through the Ramos System, a multimodal capture device in real time and space in the classroom; b) secondly, compare and discuss the existing nomenclatures, types and functions of erasures in view of the existing variation in the area; and, c) finally, to verify which more occur, comparing Brazilian students with Portuguese students. Since the protocol for data collection used in the two countries was the same, we need to answer which functions are most used and what the erasures are in both groups.

KEYWORDS: Textual genetics. Erasure functions. Creation process. Types of erasure.

\footnotetext{
${ }^{1}$ Mestranda no Programa de Pós-Graduação em Linguística e Literatura, PPGLL, da Universidade Federal de Alagoas (UFAL).E-mail: dayoliveira92@,hotmail.com

2 Doutora em Linguística-Universidade Federal de Alagoas (UFAL). Professora associada da Faculdade de Letras da Universidade Federal de Alagoas e do Programa de pós-graduação em Linguística e Literatura (PPGLL). E-mail: cristinafelipeto@,fale.ufal.br
} 


\section{INTRODUÇÃO}

Este artigo é um esforço no sentido de contribuir com os estudos em gênese textual que (raramente) $)^{3}$ focalizam crianças de 7 anos que escrevem de forma colaborativa, em díades, seus primeiros textos. Assim, ele se organiza do seguinte modo: inicialmente, apresentaremos, ainda que brevemente, o campo da Genética Textual, seu nascimento e, em seguida, nos centraremos sobre um de seus principais conceitos, a rasura, e a forma como diferentes autores classificam suas funções (Fabre, Grésillon e Biasi) e tipos (Felipeto, Calil).

Dando seguimento, explicaremos os aspectos metodológicos do protocolo adotado para a coleta e o recorte dos dados. Como se verá, trata-se do Sistema Ramos ${ }^{4}$, ferramenta que permite acesso a todo o processo de produção textual, desde o momento em que os alunos combinam a história até o momento em que a concluem. Na sequência, procederemos à análise dos dados e à discussão dos resultados, esperando mostrar, por exemplo, com quais funções de rasura os alunos desta faixa etária estão mais familiarizados e com quais têm mais dificuldades de operar.

\section{0 estudo da gênese textual}

A Crítica Genética é um novo campo interdisciplinar ${ }^{5}$ que surgiu com a compra, feita pela Biblioteca Nacional da França, de uma importante coleção de Haine, em 1966 e a necessidade de analisá-la e documentá-la. A partir disso, no ano de 1968, o CNRS (Centre National de La Recherche Scientifique) criou uma equipe de pesquisadores, fundada e dirigida por Louis Hay, encarregada de classificar, explorar, editar e analisar essa coleção ${ }^{6}$. A nova corrente recebeu esse nome, conforme Grésillon (1991), após a publicação de uma coletânea publicada por Louis Hay, os Essais de Critique Génétique (em 1979, pela Editora Flammarion) e, desde então, tem apresentado um rápido crescimento, de acordo com Kamada (1997): sua "eficácia interpretativa", segundo este autor, tem permitido à Crítica Genética "ampliar seu campo de aplicação. Assim, obras teatrais, filosóficas, até mesmo pictóricas e arquitetônicas figuram entre as reflexões genéticas propostas até então" (1997, p. 67).

Como decorrência da expansão de seu campo, Doquet (2003) propõe a substituição do nome "Crítica Genética" para "Genética Textual", uma vez que o termo "Crítica" aparece sempre muito relacionado à "coisa literária" e não abrange, certamente, o conjunto das pesquisas preocupadas com o processo de produção, seja de uma peça teatral, de uma obra literária ou, como em nosso caso, de processos de escrita produzidos em sala de aula.

Faz-se crítica genética quando se analisa um documento autógrafo para compreender, no movimento da escritura, os mecanismos da produção; quando se investiga os caminhos percorridos pelo escritor e se verifica o processo que precedeu ao nascimento da obra e, também, quando se elaboram conceitos, métodos e técnicas que permitam explorar, cientificamente, o precioso patrimônio que os manuscritos conservados nas coleções e arquivos representam.

Para Grésillon, este novo campo tem como objetivo a descrição e a exploração dos mecanismos de escritura, confronta o que o texto foi com o que poderia ter sido, contribuindo, assim, para relativizar a noção de texto fechado, concluído e para dessacralizar a própria noção de

\footnotetext{
${ }^{3}$ São escassos os estudos que analisam processos (e não o produto) de escrita do qual participam alunos entre 7 e 8 anos, recém-alfabetizados e que escrevem seus primeiros textos. Alguns são propostos por Felipeto (2012, 2019) e Calil (2008, 2011).

${ }^{4}$ Um sistema de captura multimodal (visual, sonora e escrita) capaz de oferecer ao pesquisador informações simultâneas do processo de escritura no tempo e espaço real da sala de aula (contexto ecológico e didático).

${ }^{5}$ Em geral, as abordagens em Genética Textual adotam a Linguística da Enunciação (Benveniste, Authier-Revuz), o Dialogismo bakhtiniano e a Psicologia Cognitiva.

${ }^{6}$ Muitos outros manuscritos surgiram posteriormente, inclusive, manuscritos de Saussure e Benveniste. Para maiores informações, indicamos o site do ITEM: http://www.item.ens.fr
} 
Texto (GRÉSILLON, 1991, p.7-8), de modo que é necessário confrontar a obra de todas as maneiras possíveis, levando em consideração o seu processo de escrita (o escrever, o apagar, o rasurar, o reler, o acrescentar etc.), ou seja, o que antecede e procede a sua escritura.

Nesta mesma direção vai Fenoglio, quando afirma que "a genética dos textos visa [...] elucidar o trabalho da escritura e interpretar seu processo". Para este fim, segundo a autora, "ela passa por uma análise das versões sucessivas em seus diferentes estados, mas nenhuma hierarquia obedece a um juízo de valor: tudo é levado em conta" (2013, p. 21). Esta pesquisadora ressalta, ainda, que, inicialmente, a disciplina genética foi fundada com base nos manuscritos de escritores, entretanto, houve um avanço em relação ao objeto de análise e hoje essa corrente está diversificada em função dos gêneros e tipos textuais materializados pelos manuscritos literários, científicos, de direito, etc., bem como os manuscritos de alunos recém-alfabetizados, que são o objeto dessa pesquisa.

De acordo com Grésillon, o manuscrito

porta os traços de um ato, de uma enunciação em marcha, de uma criação que está sendo feita, com seus avanços e seus bloqueios, seus acréscimos e seus riscos, seus impulsos frenéticos e suas retomadas, seus recomeços e suas hesitações, seus excessos e suas faltas, seus gastos e suas perdas (GRÉSILLON, 2007, p. 52).

Assim, o ato de escrever requer necessariamente o uso de rasuras, a tal ponto que Barthes, em um seminário na Rapp Square (1976), pronunciou: "La litterature c'est la rature". A esse propósito, Biasi comenta:

A obra literária escrita no primeiro rascunho sem a menor correção é provavelmente uma ficção, uma fábula que só tem credibilidade a partir do cruzamento entre uma certa ideia histórica de heroísmo intelectual [...] e a existência de textos publicados ou completos cujos rascunhos e arquivos preparatórios desapareceram completamente (BIASI, 1996, p. 01).

Se escrever parece ser indissociável do ato de rasurar, no próximo tópico, abordaremos os tipos e as funções da rasura apresentados pelos autores aqui analisados, os quais serão confrontados e discutidos.

\section{Funções da rasura}

Como dissemos anteriormente, o objetivo desta seção é realizar um estudo comparativo acerca dos tipos e das funções da rasura a partir dos trabalhos de três geneticistas, a saber, Almuth Grésillon (1991, 2007), Pierre-Marc de Biasi (1996) e Claudine Fabre (1986, 1987).

É possível descobrir os mecanismos que envolvem a criação textual através da análise do processo de produção por meio dos tipos e das funções das rasuras feitas pelos escreventes. Acerca da rasura, Grésillon afirma que ela possui um caráter paradoxal, uma vez que é

\footnotetext{
simultaneamente perda e ganho. Ela anula o que foi escrito ao mesmo tempo em que aumenta o número de vestígios escritos. É nesse próprio paradoxo que repousa o interesse genético da rasura: seu gesto negativo transforma-se para o geneticista em tesouro de possibilidades, sua função de apagamento dá acesso ao que poderia ter se tornado texto (GRÉSILLON, 2007, p. 97).
}

Ou seja, à medida que o autor apaga algum termo, ele acrescenta outro que julga mais apropriado para o seu texto. Essa anulação, formada por intermédio da rasura, se transformará em novas possibilidades de escrita.

Conforme aborda a geneticista, a rasura apresenta três funções: a primeira, a que fornece opções para a reescritura é a substituição, "as duas outras servem seja para deslocar, seja para 
suprimir definitivamente" (GRÉSILLON, 2007, p. 100). Para Grésillon, reescreve-se para conseguir melhor adequação do texto, desloca-se porque se julga que determinada unidade fica melhor acima ou abaixo no texto e "suprime-se para estreitar, renunciar, rejeitar, censurar, etc." (GRÉSILLON, 2007, p.100).

Neste mesmo cenário, Biasi (1996) aborda aspectos positivos e negativos da rasura apresentados por alguns escritores: Flaubert a considera como instrumento essencial da escrita; Stendhal a vê como último recurso e Aragão diz que muitos as usam, mas tentam evitá-la de todas as formas ou limitam seu uso somente na fase preparatória do trabalho. Biasi expõe, ainda, que alguns escritores são tão alérgicos às rasuras que preferem não usá-las; assim, acumulam uma sucessão de versões para obterem melhor aparência.

Biasi (1996) afirma que a rasura está, inevitavelmente, ligada a uma ideia negativa: "é um revés da escrita que é exibido e se encaixa com certa indecência no espaço da página" (p. 18), e isso, para o escritor, é algo doloroso, um constrangimento para o olho, uma má lembrança assombrosa da mente, um obstáculo para escrever que tropeça em si mesmo, por isso, alguns escritores odeiam as rasuras e preferem desperdiçar papel e praticar o que o autor chama de rasura branca.

Biasi (1996) apresenta a rasura como um componente complexo da escrita, e de acordo com sua funcionalidade podem ser rasuras de substituição, supressão ou exclusão, uso ou gestão, transferência ou deslocamento e suspensão dilatória ou provisória, sendo as mais conhecidas as de supressão e as de substituição, esta última a mais complexa.

Biasi (1996, p. 10) define as seguintes funções apresentadas anteriormente:

1. Substituição: é um traço marcado na decisão de cancelar um segmento previamente escrito para substituir outro segmento;

2. Supressão: eliminação do segmento sem substituição;

3. Uso ou gestão: é usada para registrar o fato de que um segmento foi o objeto da exploração ou uma reescritura; ou seja, o escritor faz uma lista de termos e à medida que faz uso de um termo determinado, ele o anula para saber que já foi utilizado.

4. Transferência ou deslocamento: é usada para marcar o projeto ou ato de mover um segmento escrito para reinserção em outra área do mesmo contexto escrito;

5. Suspensão dilatória ou provisória: forma particular de rasura para delimitar o espaço de uma futura rasura, em marcação de um segmento que pode dar lugar a um eventual cancelamento ou correção posterior. Como exemplo, é quando uma palavra fica acima ou abaixo de outra palavra e, posteriormente, o escritor escolhe qual permanecerá em seu texto, provocando assim uma rasura.

Desses cinco mecanismos distintos (substituição, eliminação, transferência, gestão e suspensão) Biasi expressa que os dois primeiros designam gestos de escrita, enquanto os outros três são formas mais raras.

Biasi aponta que, em princípio, a rasura é um procedimento manuscrito, mas que existem diversas formas de rasuras impressas, nas quais a branca e a errata estão presentes. $\mathrm{O}$ autor reflete que, na maioria dos casos, a rasura é uma operação que ocorre uma vez em um segmento escrito pra excluí-lo, substituí-lo, excluí-lo, movê-lo e suspendê-lo.

Com uma nomenclatura diferente, em vez de rasura, Fabre (1986) traz o termo variante, que, de acordo com Grésillon (2007) significa a diferença entre dois estados de texto, e que, "tanto "variante" quanto "rasura" evocam [...] intervenções pontuais, locais, efetuadas em ordem dispersa, e sugerem gestos completamente atomizados" (GRÉSILLON, 2007, p. 109). Nas palavras de Fabre, considerar esses diferentes momentos da inscrição ou estados de texto nos permite diferenciar as modificações feitas de modo imediato e as que ocorrem após a releitura.

Em relação às operações envolvidas nas variantes, Fabre adota a terminologia proposta por Bellermin-Noel, Grésillon e Lebrave; entretanto, diferente deles, seu trabalho está voltado ao 
campo da escrita de crianças em idade escolar, enquanto o dos autores citados trata dos manuscritos literários de escritores experientes.

De acordo com os pesquisadores expostos por Fabre (1986, p. 69), essas variantes incluem quatro "tipos":

1. Adição: Um retorno ao escrito, que pode ser de um elemento gráfico, um acento, uma pontuação, um grafema, uma palavra e uma ou mais frases.

2. Supressão/Exclusão: quando não há substituição do elemento excluído e que pode estar relacionado a várias unidades, como a acentuação, o grafema, a sílaba, um sintagma e uma ou mais frases.

3. Substituição: quando há uma exclusão seguida de um novo termo. Ela lida com um grafema, uma palavra, uma frase ou em conjuntos maiores.

4. Deslocamento: permutação de elementos, o que resulta na modificação de sua ordem na cadeia.

Fabre não esclarece a distinção entre "tipo" e "função" e faz uma confusão entre os dois termos; ora ela aborda um, ora outro; não explicando qual seria a diferença entre eles, diversamente dos dois pesquisadores aqui discutidos, Biasi e Grésillon, que abordam o termo função.

Segundo a autora, esses "tipos", aos quais adotaremos como "funções" em nosso trabalho, são claramente distinguíveis na condição de escrita legível, condições essas nem sempre aplicadas por escreventes novatos. É importante esclarecer essa diferença entre tipo e função, visto que trataremos dos dois termos de forma distinta em nossa análise.

\begin{tabular}{|c|c|c|}
\hline & FUNÇÕES DA RASURA \\
\hline GRÉSILLON & BIASI & FABRE \\
\hline Substituição & Substituição & Substituição \\
\hline Supressão & Supressão & Supressão/Exclusão \\
\hline Deslocamento & Transferência ou deslocamento & Deslocamento \\
\hline & Uso ou gestão & Adição \\
\hline & Suspensão dilatória ou provisória \\
\hline \multicolumn{2}{|c|}{ Tabela 1: Funções da rasura } \\
\hline & Fonte: Laboratório do Manuscrito Escolar
\end{tabular}

Diante das considerações expostas pelos autores citados, acerca das definições das funções de rasura, é possível observar semelhanças e diferenças nos trabalhos. Mesmo alguns apresentando diferentes nomenclaturas, todos os autores citados falaram das rasuras de supressão, substituição e deslocamento, restando as rasuras de adição, apresentada por Fabre (1986), as de uso/gestão e as de suspensão apresentadas por Biasi (1996).

Na próxima parte do trabalho, iremos apresentar a metodologia utilizada na coleta dos dados, bem como explicar, de forma sucinta, como se deu o processo de produção dos textos.

\section{Procedimentos metodológicos}

Os dados em análise pertencem ao LAME - Laboratório do Manuscrito Escolar, da Universidade Federal de Alagoas - UFAL (Brasil) e foram coletados através dos seguintes procedimentos: após diversas leituras de histórias em casa e na escola, sugeridas pelas professoras, os alunos são instruídos a formarem duplas, pois participam de uma situação de escrita colaborativa, descrita por Felipeto (2019) como uma situação em que dois ou mais participantes assumem a tarefa de escreverem, juntos, um único texto; condição essa que a autora considera privilegiada, visto que, nela, pode ser observada a gênese da escrita pela oralidade, bem como a oralidade criando a escrita; assim evidencia-se, através de seus trabalhos, a vantagem do uso da escrita colaborativa em sala de aula. Para isso, a dupla precisa combinar a história a ser inventada e 
os alunos se alternam a cada escrita, de modo que, a cada vez, um fica responsável por escrever e o outro por ser o ditante, aquele que vai acompanhando e lembrando o que foi combinado.

Felipeto (2019) afirma que a presença do outro na escrita colaborativa faz com que haja, de forma ampla, um processo de reflexão sobre a linguagem, posto que esse processo "favorece uma explicitação dos saberes, já que a interação demanda uma negociação e resolução dos problemas concretos que surgem durante a escrita" (FELIPETO, 2019, p.135). A pesquisadora expõe, ainda, que, do ponto de vista didático-metodológico, "a produção textual colaborativa diática (escrever a dois um único texto) permite que tenhamos acesso ao que os alunos pensam enquanto escrevem, a partir do diálogo estabelecido pelos alunos" (p. 135), fato que contribui para a análise dos conhecimentos que estão ou não em curso. A situação de escrita colaborativa na escola nos permite observar características do processo de aprendizagem da escrita e as estratégias utilizadas pelos alunos na resolução dos problemas que surgem durante esse processo.

Após o momento de combinação, é dada à dupla uma folha com micropontos para a criação da história e uma caneta smartpen, que registra a escrita "se fazendo" em tempo real. Em seguida, ocorre o momento da formulação e, por último, há a releitura do que foi escrito para alterar, caso seja preciso.

No Brasil, os dados foram recolhidos em uma escola de Maceió-AL, em uma turma de $2^{\circ}$ Ano do ensino fundamental. A filmagem escolhida foi gravada no dia 20/04/2012 e os diálogos foram produzidos para a criação do texto "Porque a girafa tem o pescoço longo", inventado pelas alunas $\mathrm{M}$ e $\mathrm{S}$ (escrevente), ambas com 7 anos de idade na época. Em Portugal, os dados foram coletados em uma escola de Aveiro, em uma turma de $2^{\circ}$ Ano do ensino fundamental. A filmagem foi gravada no dia 06/02/2015 e os diálogos foram produzidos para a criação do texto "A Branca de Neve e os três dinossauros", inventado pelas alunas B (escrevente) e L, ambas também com 7 anos de idade.

Vale dizer que a coleta nos dois países (Brasil e Portugal) seguiu o mesmo protocolo e houve formação dos professores com relação aos procedimentos a serem seguidos, como a apresentação da consigna, a orientação para que, em caso de rasura, os alunos colocassem o elemento rasurado entre parênteses ou passassem apenas um traço, com vistas a preservar e observar o que foi "apagado". Toda a filmagem, áudio e captura dos momentos antes, durante e depois da produção escrita foi realizada por meio do Sistema Ramos, em que

\begin{abstract}
O registro visual é feito através de câmeras de vídeo, capturando o contexto da sala de aula e a interação entre alunos e professor; o registro sonoro é feito através de gravadores digitais e microfones, capturando a fala espontânea dos alunos escreventes e o diálogo entre os participantes; o registro escrito é feito através de uma caneta inteligente e do programa HandSpy, capturando o traço da tinta na folha de papel (CALIL, 2019, p. 1).
\end{abstract}

Juntos, esses instrumentos formam um filme sincronizado capaz de capturar em tempo real todos os momentos e movimentos da sala de aula de modo ecológico e didático.

A seguir, apresentaremos a análise dos dois textos descritos acima, ressaltando quais as funções e os tipos de rasura encontrados nas produções textuais de crianças recém-alfabetizadas aqui analisadas.

\title{
4 Análise de dados
}

Abaixo, apresentaremos alguns exemplos das funções e dos tipos de rasura encontrados nos processos analisados, classificados a partir das propostas apresentadas pelos teóricos aqui discutidos. Nos manuscritos analisados, as alunas retornaram para reformular o texto devido a problemas em níveis diversos: de acentuação, antecipação, gráficos, ortográficos, de pontuação e sintáticos. Para demonstrar exemplos concretos de cada função e tipo de rasura, destacamos alguns 
trechos da produção final das duas díades, bem como, na maioria dos casos, o diálogo produzido durante o processo dessa produção:

\subsection{Rasura ortográfica}

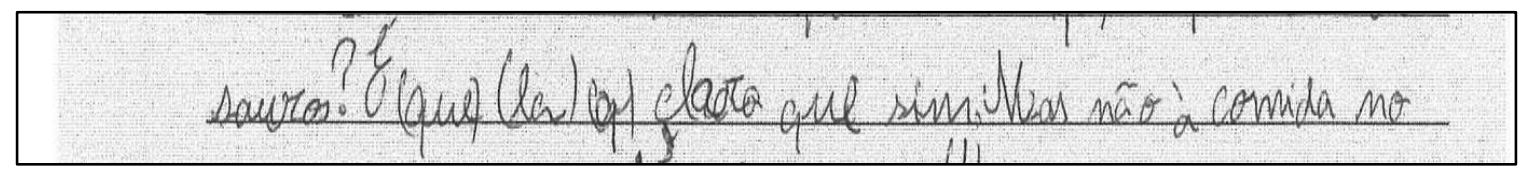

Figura 1 - Fragmento do texto "A Branca de Neve e os três dinossauros", inventado por B e L em 06/02/2015.

Fonte: Laboratório do Manuscrito Escolar (2015).

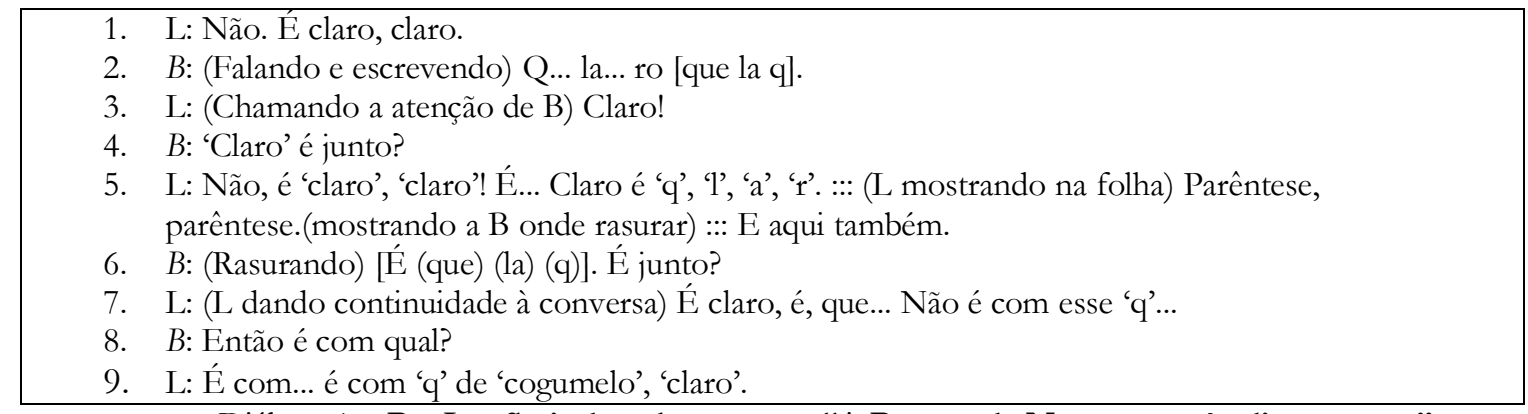

Diálogo 1 - B e L refletindo sobre o texto "A Branca de Neve e os três dinossauros” Fonte: Laboratório do Manuscrito Escolar (2015).

No exemplo acima, B fala (turno 2) pausadamente e no português europeu a sílaba "cla" da seguinte forma: "É q la ro", hipersegmentando a sílaba "cla", por causa do som /k/, que, neste caso específico, produz confusão por causa da homofonia entre "q" (seguido sempre de "u" no português) e "c", grafemas que representam o fonema /k/. L, por sua vez, nos turnos 3 e 5 soletra a B como se escreve "claro", mas ela própria representa o fonema / $\mathrm{k} /$ através do grafema "q" ao dizer, no turno 5, " É... Claro é 'q', 'l', 'a', 'r'". No entanto, no turno 7 afirma que "não é com esse 'q"' e, no turno 9, diz "é com 'q' de 'cogumelo', 'claro"'. A preocupação quanto à grafia da palavra "claro", com "ql" no início da palavra, configura um problema ortográfico, porém, a rasura sinaliza o reconhecimento desse erro através da posterior reescrita correta da palavra. Neste caso, temos um exemplo de rasura de substituição. A rasura ortográfica é aquela que, segundo Gak (1976, p. 23, apud FELIPETO, 2012, p. 99) estuda as regras que determinam o emprego das grafias conforme as circunstâncias e que só é questão de ortografia quando há a possibilidade de escolha entre duas grafias diferentes.

\subsection{Rasura de antecipação}

A seguir, apresentaremos um exemplo de rasura que, de acordo com Fabre (1986), é aquela provocada devido a uma dessincronização entre a parte motora e a velocidade do pensamento.

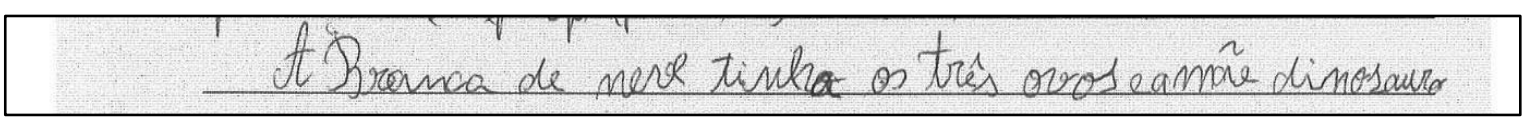

Figura 2 - Fragmento do texto: “A Branca de Neve e os três dinossauros”, inventado por B e L em 06/02/2015.

Fonte: Laboratório do Manuscrito Escolar 2015. 


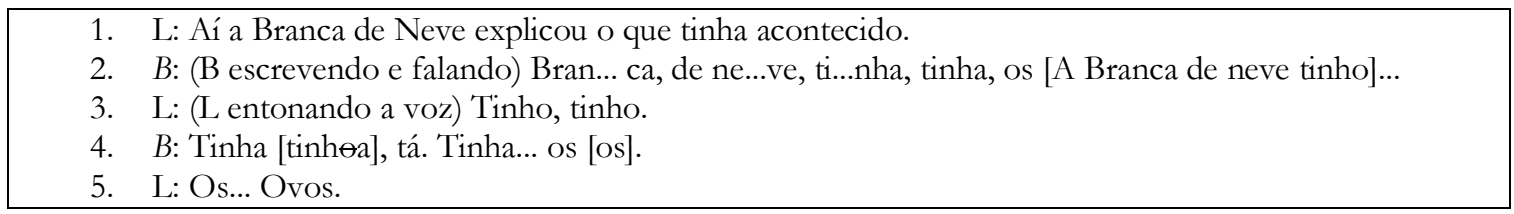

Diálogo 2 - B e L refletindo sobre o texto "A Branca de Neve e os três dinossauros" Fonte: Laboratório do Manuscrito Escolar 2015.

Através da análise do vídeo é possível observar que, no turno 2, B já havia verbalizado "tinha os" enquanto começava a escrever "ti", de modo que o "o" do artigo "os" é antecipado em "tinho". No turno 3, L estranha a escrita de "tinho" e chama a atenção de B, que reconhece a antecipação e a rasura. Esse reconhecimento é marcado pela rasura de substituição, que vem corrigir a antecipação através da supressão do "o" e sua substituição pelo "a", como pode ser visto no traço reforçado do "a": tinhea. Assim, a rasura de substituição é marcada por um duplo movimento: o apagamento de um elemento e a adição, em seu lugar, de um outro, que substitui o primeiro. A rasura de antecipação, por sua vez, resulta da combinação entre a antecipação e seu reconhecimento através da rasura.

No exemplo abaixo, apresentamos um tipo de rasura que foi adicionado, mas que não apresenta marcas de rasura, portanto, só pode ser percebido por meio do processo, já que, na maioria das vezes, é imperceptível no produto final. Como consideramos a rasura como um retorno ao já escrito, a adição da vírgula a seguir também é considerada uma rasura.

\subsection{Rasura de pontuação}

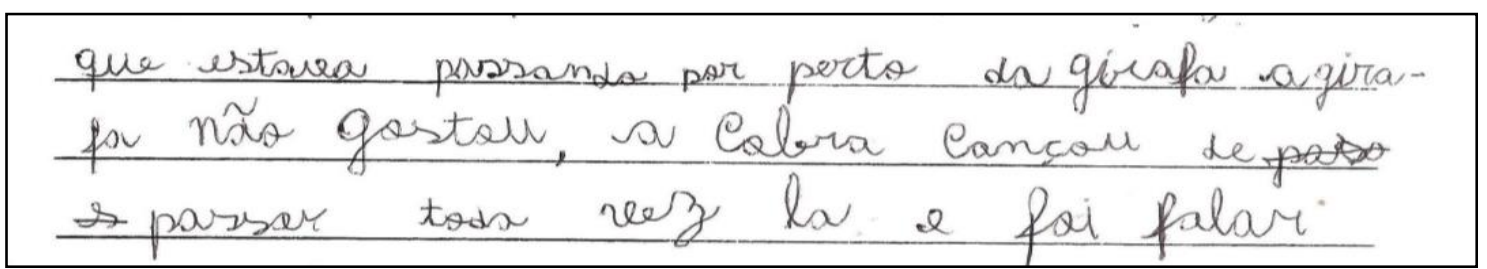

Figura 3 - Fragmento do texto "Por que a girafa tem o pescoço longo", produzido por S e M em $20 / 04 / 2012$

Fonte: Laboratório do Manuscrito Escolar, 2012.

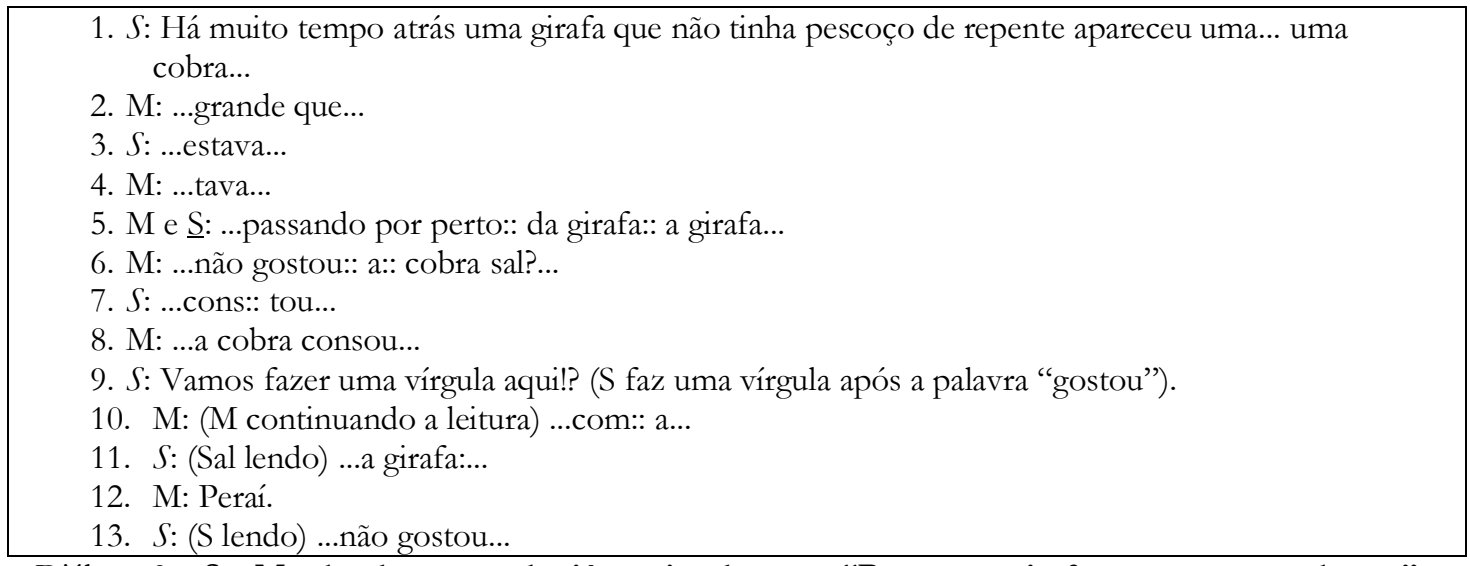

Diálogo 3 - S e M relendo um trecho já escrito do texto "Por que a girafa tem o pescoço longo" Fonte: Laboratório do Manuscrito Escolar (2012).

No exemplo acima, S e M estão relendo o que já haviam escrito (figura 3). A adição da vírgula foi feita após a releitura do trecho "a cobra não gostou" (turnos 6 a 9), quando a escrevente $\mathrm{S}$ sugere à colega $\mathrm{M}$ a colocação desse sinal de pontuação (turno 9). Em seguida, a vírgula é imediatamente acrescentada por S, mesmo sem M responder sim ou não, fato não tão perceptível 
no diálogo, mas que foi comprovado por meio da análise do vídeo, separando, desse modo, duas orações com sujeitos diferentes. O exemplo seguinte traz uma rasura de supressão, que foi eliminada porque o termo já havia sido grafado, evitando assim a repetição do mesmo.

\subsection{Rasura sintática}

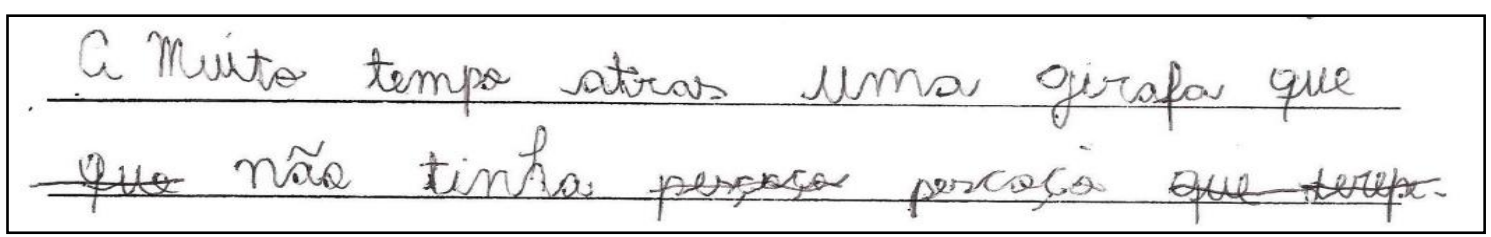

Figura 4 - Fragmento do texto "Por que a girafa tem o pescoço longo", produzido por S e M em $20 / 04 / 2012$.

Fonte: Laboratório do Manuscrito Escolar 2012.

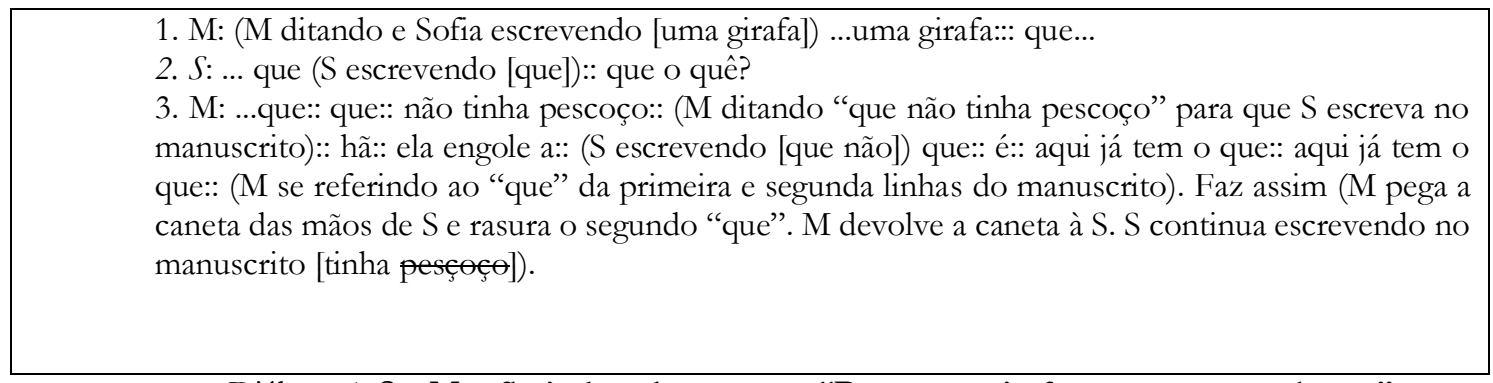

Diálogo 4: S e M refletindo sobre o texto "Por que a girafa tem o pescoço longo"

Fonte: Laboratório do Manuscrito Escolar (2012).

Com relação ao trecho e ao diálogo que lhe corresponde acima, podemos dizer que a supressão do segundo "que" pode ser considerada uma rasura sintática, uma vez que eliminou a repetição do termo. A sintaxe diz respeito à organização das palavras dentro das frases ou orações e suas relações entre si, no que diz respeito à concordância, subordinação e ordem. Os textos com problemas relacionados à estrutura sintática geralmente apresentam períodos truncados, justaposição de palavras, ausência de termos ou excesso de palavras, como é o caso apresentado, podendo haver ainda a presença de pontuação indevida ou ausência de pontuação, o que interfere na qualidade da estrutura sintática. Abaixo, mostraremos outro exemplo de rasura sintática, mas agora através da função de deslocamento:

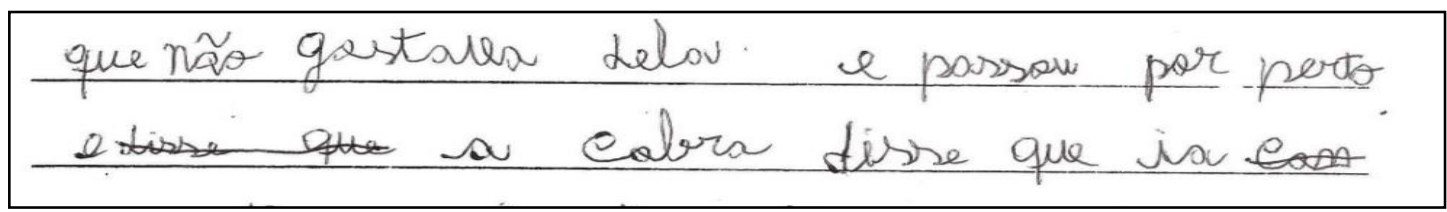

Figura 5 - Fragmento do texto "Por que a girafa tem o pescoço longo", produzido por S e M em $20 / 04 / 2012$.

Fonte: Laboratório do Manuscrito Escolar 2012.

\footnotetext{
1. $S$ : (Escrevendo [dela]) e:: passou por per...to (S escrevendo [passou por perto].

2. M: ... e:: passou por perto (M lendo):: e disse que ela:: que:: disse que ela ia competir ( $\mathrm{S}$ escrevendo [e disse que])...

3. $S:$... quem ia competir?...

4. M: ...queria competir:: aí:: quem ganhar pode fazer o que quiser:: aí ela não aceitou:: aí pisou nela e engoliu:: (M lendo o manuscrito) que:: e disse que::

5. S: (S rasura [disse que])... botar assim:: e a cobra (S falando e escrevendo [e a cobra])...

6. M: ...gira:: a cobra:: (M lendo "a cobra", que $\mathrm{S}$ está escrevendo) pediu pra...
} 
7. $S:$...dis::... se:: que ia (S escrevendo [disse que ia])...

Diálogo 5: S e M refletindo sobre o texto "Por que a girafa tem o pescoço longo" Fonte: Laboratório do Manuscrito Escolar, 2012.

Percebe-se que houve um deslocamento do termo "disse que", que foi colocado mais à frente, mas na mesma linha. Como já mencionado acima, Grésillon (2007, p.100) diz que ocorre deslocamento quando se julga que determinada(s) unidade(s) fica(m) melhor acima ou abaixo no texto, entretanto os dois deslocamentos encontrados em nossas análises são colocados mais à frente, na mesma linha. Para Biasi (1996), ocorre deslocamento quando um segmento escrito é movido para reinserção em outra área do mesmo contexto escrito, o que ocorre no exemplo acima. O que parece estar em jogo é o sujeito do discurso indireto "disse que", de modo que no turno 3, $\mathrm{S}$ pergunta "quem ia competir?" A própria aluna $\mathrm{S}$, no turno 5 , recupera o referente ao suprimir "disse que", escrever logo em seguida "a cobra" e readicionar "disse que" na cadeia textualdiscursiva. O deslocamento, então, é uma função composta por supressão + adição ou reaparecimento do elemento deslocado em outro lugar. Abaixo, exemplificamos um caso de rasura de substituição devido a um problema gráfico.

\subsection{Rasura gráfica}

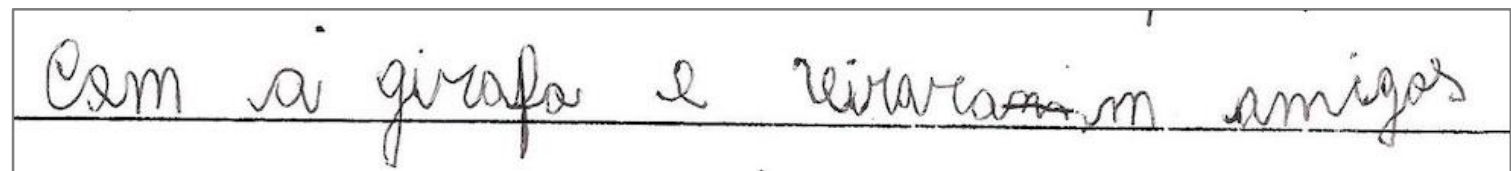

Figura 6. Fragmento do texto "Por que a girafa tem o pescoço longo", produzido por S e M em 20/04/2012 Fonte: Laboratório do Manuscrito Escolar 2012.

Considerando que a substituição é formada por uma supressão + adição, no exemplo acima, vemos a supressão do ' $\mathrm{m}$ ' em 'viraram' e sua readição. Através da análise do vídeo é possível observar que aos 00:18:28, S leva a mão que apoiava a folha à cabeça, o que faz com que ela entorte levemente e o ' $\mathrm{m}$ ' saia com a última "perna" mais baixa e torta, como pode ser visto na figura 6 acima. Abaixo, mostramos o momento em que $\mathrm{S}$ eleva a mão à cabeça:

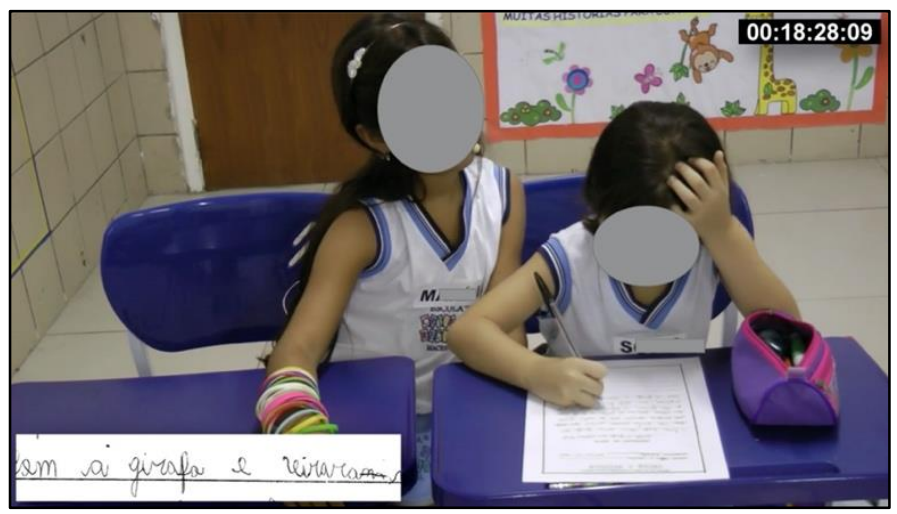

Figura 7. Texto "Por que a girafa tem o pescoço longo", produzido por S e M em 20/04/2012 Fonte: Laboratório do Manuscrito Escolar 2012.

No entanto, não há comentários nem de $\mathrm{S}$, nem de $\mathrm{M}$ acerca desta rasura, que só pode ser compreendida através da análise do vídeo. Abaixo, apresentamos um exemplo ilustrativo de rasura de acentuação. 


\subsection{Rasura de acentuação}

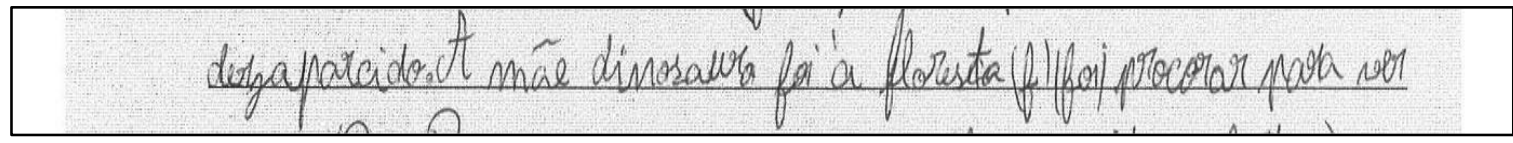

Figura 8. Fragmento do texto: “A Branca de Neve e os três dinossauros” inventado por B e L em 06/02/2015.

Fonte: Laboratório do Manuscrito Escolar 2015.

1. B: Pera. A mãe [A mãe] $\llcorner$ (L ditando ao mesmo tempo) di... no... sal-ro [dinossauro]

2. L: Dinossauro... Foi à floresta...

3. B: Fo-i a [foi a]...

4. L: (L entonando a voz e gesticulando com o dedo na carteira) 'a', 'a'.

5. B: [à] (B ditando enquanto escreve) flo-res-ta [floresta] floresta.

6. L: Ver se a, Branca de Neve....

7. B: Não. Foi à casa da. Branca de Neve.

8. L: Foi à... floresta.

Diálogo 6: B e L refletindo sobre o texto "A Branca de Neve e os três dinossauros" Fonte: Laboratório do Manuscrito Escolar (2015).

Percebe-se, após a leitura do diálogo produzido pela díade $\mathrm{B}$ e L, que uma crase foi adicionada ao 'a' no turno 5 . L constata, no turno 4, que naquele 'a' deveria ser colocado uma crase, entretanto L não expõe de modo claro que B deve colocar este acento, talvez por ter esquecido o nome dele, por isso gesticula e B logo entende o acento que deve ser acrescentado. Como se trata de uma rasura de adição, ela é, muitas vezes, imperceptível no produto final, e só é percebida a partir da análise do processo; nesse caso, identificada por meio do vídeo e do diálogo produzido entre a dupla. Neste caso, a crase ocorreu porque houve a fusão de duas vogais idênticas, relacionadas ao emprego da preposição "a" com o artigo feminino "a".

\section{Resultados}

Os gráficos 1 e 2 abaixo comparam as funções da rasura mais utilizadas por alunos brasileiros e portugueses. Vale dizer que a maior parte das escolas em Portugal adota o método fônico para alfabetização dos alunos e nesta escola brasileira é o método construtivista. As duas funções mais utilizadas são a de substituição e a de supressão, corroborando o que diz Biasi (1996), qual seja, que a substituição e a eliminação (supressão) são as funções mais comumente utilizadas.

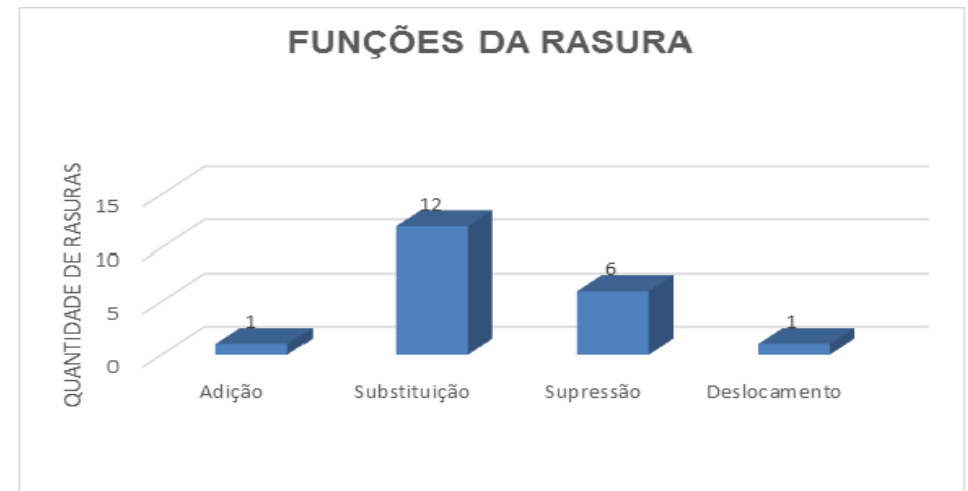

Gráfico 1: Funções e quantidade de rasuras encontradas no texto da díade brasileira S e M Fonte: Laboratório do Manuscrito Escolar 


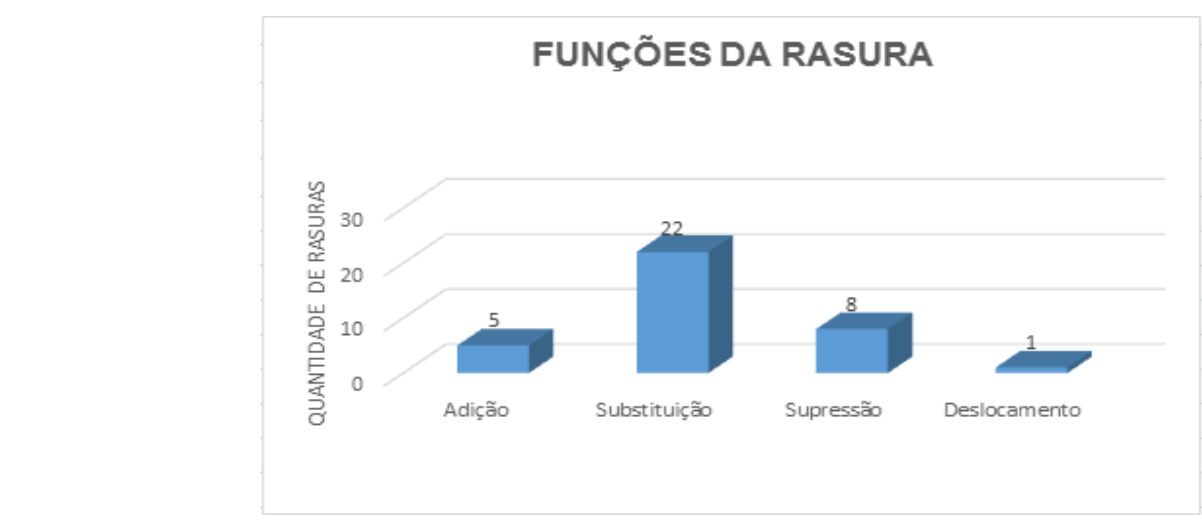

Gráfico 2: Funções e quantidade de rasuras encontradas no texto da díade portuguesa B e L Fonte: Laboratório do Manuscrito Escolar

Os gráficos 3 e 4 mostram a incidência de rasuras nos dois grupos, o que poderíamos formular através da pergunta: quando os alunos rasuram, rasuram o quê? $\mathrm{Na}$ dupla brasileira, a maior parte das rasuras foi de ordem gráfica, ou seja, houve uma maior preocupação com a forma (traçado) de uma letra, de uma sílaba. Em segundo lugar, a sintática, indicando uma maior preocupação com a ordem dos elementos na frase, sua repetição e/ou ausência de referente. A rasura de tipo ortográfico aparece em $3^{\circ}$ lugar e, embora a ortografia seja uma questão para alunos do $2^{\circ}$ ano do ensino fundamental, podemos ponderar que questões ortográficas já podem ter sido resolvidas, em grande parte, no $1^{\circ}$ ano, por se tratar de uma escola privada. Acreditamos, inclusive, que uma preocupação maior com a disposição dos elementos no texto (rasuras de tipo sintático) indica um olhar mais macrotextual.

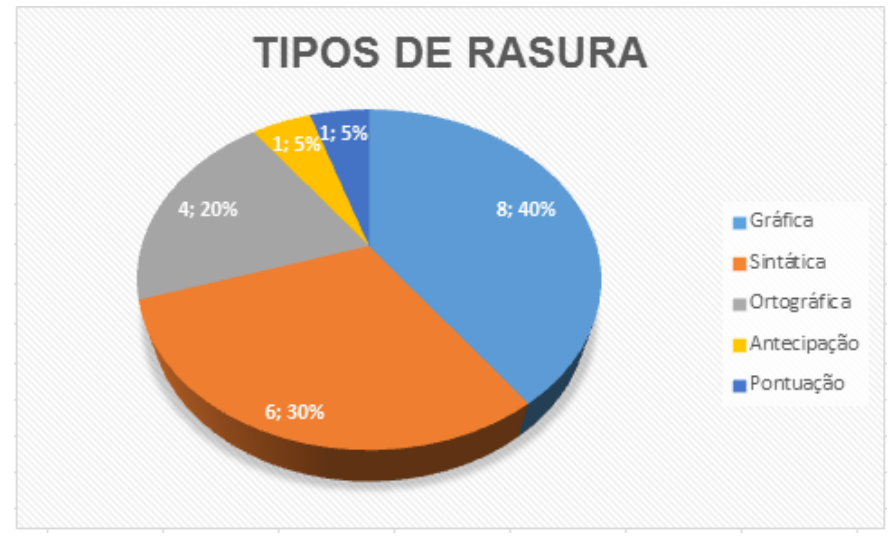

Gráfico 3: Tipos e quantidades de rasura produzidos pela díade brasileira $\mathbf{S}$ e $\mathbf{M}$ Fonte: Laboratório do Manuscrito Escolar

$\mathrm{Na}$ dupla portuguesa (gráfico 4), a incidência maior é sobre questões ortográficas e, depois, gráficas. Pela análise dos dados e baseados no método de ensino utilizado observamos que questões envolvendo o som das letras e qual delas utilizar ainda está no cerne das preocupações das alunas, a exemplo do que ocorre na figura 1 e diálogo 1 ("é q la ro que há"), com ênfase ao fonema /k/.

Outros tipos de rasuras, tais como de pontuação, antecipação e acentuação ocorreram com menor frequência. No entanto, gostaríamos de assinalar o conhecimento implícito, pois que não verbalizado, que aparece na fig. 8, diálogo 6 ("foi à floresta). Nele, L insiste em mostrar à B que havia, ali, a necessidade de uma crase e, sem explicitar este termo linguístico e repete com ênfase "a... a...", além de gesticular na carteira a direção do acento. Talvez haja, aí, um "saber sem saber que sabe". 


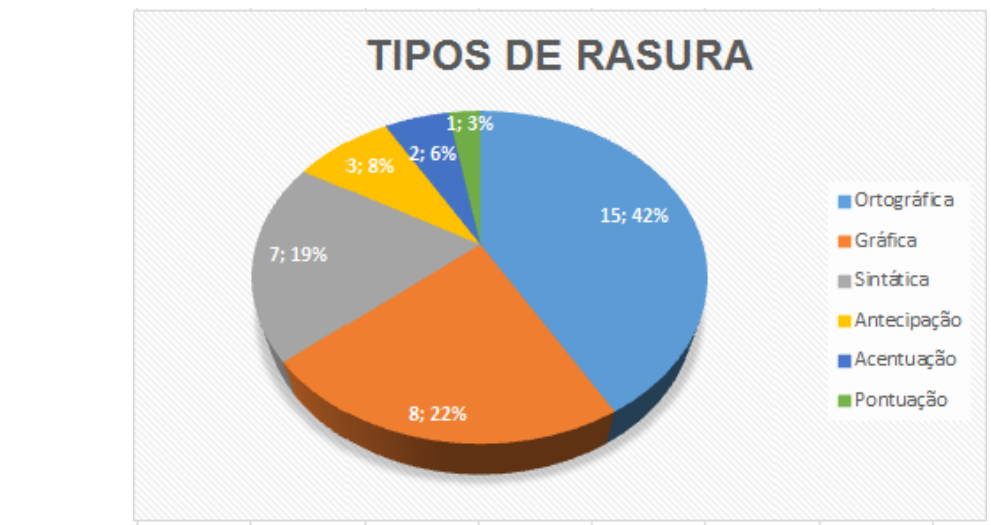

Gráfico 4: Tipos e quantidades de rasura produzidos pela díade portuguesa $\mathbf{B}$ e $\mathbf{L}$ Fonte: Laboratório do Manuscrito Escolar

\section{CONSIDERAÇÕES FINAIS}

A partir desse estudo foi possível observar que o que as crianças brasileiras e portuguesas recém-alfabetizadas, e em díades, mais rasuram está relacionado, em maior proporção, às funções de substituição e supressão, confirmando assim o que foi apresentado por Biasi (1996), quando afirma que a substituição e a supressão são gestos de escrita mais comuns, enquanto as demais funções são menos utilizadas. Entretanto, também foram encontradas as funções de adição, seis vezes ao todo, sendo cinco delas no texto português e apenas um caso no texto brasileiro; a respeito dessa função, Fabre (1987) define que ela está sempre presente nos escritos dos alunos nos três primeiros anos da escola elementar, confirmando, desse modo, o que foi encontrado em nossos dados. Além desses, foram encontrados dois exemplos de deslocamento, um em cada texto, completando, dessa maneira, o quadro das funções apresentado por Fabre.

A respeito da ocorrência das rasuras, podemos inferir que o que esses alunos mais rasuram em situações de escrita colaborativa está voltado aos seguintes tipos: ortográficos, gráficos, de pontuação, de antecipação, sintáticos e de acentuação, visto que estão trabalhando e refletindo sobre o texto que está sendo produzido. Sobre esses tipos de rasura, a ortográfica, a gráfica e a sintática apareceram mais vezes nos dois textos, dezenove, dezesseis e treze, respectivamente. Ademais, encontramos nos dois processos, dois casos de rasura de pontuação, sendo um em cada texto, quatro casos de antecipação, três deles na díade portuguesa e apenas um na díade brasileira e, por fim, dois casos de acentuação, somente na díade portuguesa.

Não identificamos em nossas análises a presença das funções de uso ou gestão, nem de suspensão, apresentadas por Biasi, uma vez que são funções mais complexas para serem realizadas por alunos recém-alfabetizados. Com este trabalho, podemos também refletir sobre quais conhecimentos estão ou não em curso a partir da ocorrência das rasuras nos textos e da análise do processo. A rasura é um elemento essencial de toda escritura, pois indicia uma reflexão que incide sobre diferentes aspectos do texto. Sua utilização, tanto como ferramenta de escritura, quanto como elemento de análise para professores e pesquisadores em geral ainda precisa ser mais expandida.

\section{REFERÊNCIAS}

BARTHES, Roland. 1976-1977- l'École des Hautes Études en Sciences Sociales. Roland Bartes, OEurres completes, par Éric Marty, Seuil, 1995, tome 3, p. 743.

BIASI, P-M. de. Qu'est-ce qu'une rature? In POUGE, B. Ratures et repentirs. Pau: PUP, 1996. 
CALIL, Eduardo. Sistema Ramos: método para captura multimodal de processos de escritura a dois no tempo e no espaço real da sala de aula. ALFA, 04/24/2019. volume 63, 2019. 33p.

DOQUET-LACOSTE, Claire. Etude génétique de l'écriture sur traitement de texte d'éleves de Cours Moyen, anée 1995-96. Thèse de Doctorat de l'Université de Paris III (Sorbonne Nouvelle) en Sciences du Langage, 633 p., 2003.

FABRE, Claudine. Des variantes de brouillon au cours préparatoire. Etudes de Linguistique Appliquée, 62, p. 59-78,1986.

FABRE, Claudine. La reescriture das l'ecriture: les cas des ajouts dans les écrits scolaires. Études de Linguistique Appliquée (E.L.A)., n 68. Paris. (tradução de José Bartolomeu Barros), (p. 15-40). 1987.

FELIPETO, Cristina. Escrita colaborativa e individual em sala de aula: uma análise de textos escritos por alunos do ensino fundamental. Alfa, São Paulo. V.63, n. 1, p. 133-152, 2019.

FELIPETO, Cristina. O que rasuram os alunos quando escrevem a dois um único texto? Questões em torno da rasura e da escrita colaborativa. Revista do GELNE/ Grupo de estudos Linguísticos do Nordeste- Vol. 14- Números 1⁄2 - Natal: UFRN, 2012 (publicado em 2013).

FELIPETO, Cristina. Rasura e interação em textos escritos colaborativamente por alunos do ensino fundamental. Calidoscópio- V.17, n. 1, janeiro-abril, 2019.

FENOGLIO, Irène. Manuscritos de linguistas e genética textual: quais os desafios para as ciências da linguagem? exemplo através dos "papiers" de Benveniste/Irène Fenoglio; tradução Simone de Mello de Oliveira, Verli Petri da Silveira, Zélia Maria Viana Paim. - Santa Maria: UFSM, PPGL-Editores, 2013.

GRÉSILLON, Almuth. Alguns pontos sobre a história da crítica Genética. Estudos avançados, 1991.

GRÉSILLON, Almuth. Elementos da Crítica Genética: ler os manuscritos modernos. Tradução de Cristina de Campos Velho Birck, Letícia Cobalchine, Simone Nunes Reis, Vicent Leclerq; supervisão da traducão de Patrícia Chittoni Ramos Remillard; prefácio de Pbilippe willemart, Porto Alegre, editora de UFRGS, 2007, 335 p.

KAMADA, Takayuki. La critique génétique à l'épreuve de la question de l'interprétation. Universidade de Shinshu. 1997. Disponível em: <https://www.gcoe.lit.nagoyau.ac.jp/eng/result/pdf/10_KAMADA.pdf>. Acesso em: 14 fev. 2020.

Submetido em 16/04/2020

Aceito em 09/09/2020 